\title{
Depression in Climacteric Women: Most Meaningful Symptoms
}

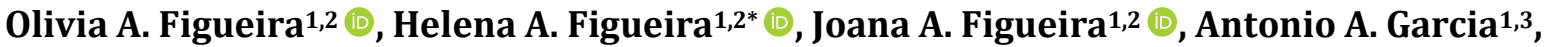 \\ Alan A. Figueira' ${ }^{1,2}\left(\mathbb{D}\right.$, Geraldo Maranhão Neto ${ }^{4}\left(\mathbb{D}\right.$, Estelio H. M. Dantas ${ }^{1,2}$ (D) \\ ${ }^{1}$ International Human Motricity Network, IHMN, Rio de Janeiro, RJ, Brazil \\ ${ }^{2}$ Laboratory of Biomedical Human Kinetics (LABIMH)/Rio de Janeiro Federal University (UNIRIO), Rio de Janeiro, RJ, Brazil \\ ${ }^{3}$ Education Department, Almeria University, Almería, Spain \\ ${ }^{4}$ Salgado de Oliveira University (UNIVERSO), Niterói, RJ, Brazil \\ Email: ^helenafigueira@gmail.com
}

How to cite this paper: Figueira, O.A., Figueira, H.A., Figueira, J.A., Garcia, A.A., Figueira, A.A., Neto, G.M. and Dantas, E.H.M. (2019) Depression in Climacteric Women: Most Meaningful Symptoms. Health, 11, 380-390.

https://doi.org/10.4236/health.2019.114034

Received: March 16, 2019

Accepted: April 25, 2019

Published: April 28, 2019

Copyright (c) 2019 by author(s) and Scientific Research Publishing Inc. This work is licensed under the Creative Commons Attribution International License (CC BY 4.0).

http://creativecommons.org/licenses/by/4.0/

\begin{abstract}
Background: With population aging occurring worldwide, promoting climacteric women's health has become the object of important studies. Purpose: Observing the prevalence of depression in climacteric women and their self-evaluation of the depression factors is the main goal of this study. Design: This cross-sectional research is enquiry descriptive. Methods: The sample was composed of 48 climacteric women (between 45 and 65 years old) non-selected volunteers, served by the Centers for Psycho and Social Attention (CAPS) of Specialized Mental Medicine, in Sorocaba, via the Beck Depression Inventory (BDI) questionnaire. Results: Checking the mean and frequency distribution, the climacteric women presented a prevalence of $37.5 \%$ of moderate depression $\left(\mathrm{BDI}_{\text {index }}=24.39 \pm 3.13\right)$, and $47.92 \%$ of severe depression $\left(\mathrm{BDI}_{\text {index }}=38.13 \pm 6.78\right)$. Concerning the symptoms, Spearman rank order correlation was found as the highest concerns, hierarchically: indecision $(\mathrm{r}=0.72, \mathrm{p}<0.001)$, anhedonia $(\mathrm{r}=0.66, \mathrm{p}<0.001)$, guilt $(\mathrm{r}=0.63$, $\mathrm{p}<0.001)$, crying $(\mathrm{r}=0.62, \mathrm{p}<0.001)$, self-esteem $(\mathrm{r}=0.60, \mathrm{p}<0.001)$, inutility $(\mathrm{r}=0.59, \mathrm{p}<0.001)$, self-criticism $(\mathrm{r}=0.58, \mathrm{p}<0.001)$ and loss of concentration $(r=0.57, p<0.001)$. Conclusions: The prevalence of depression in these CAPS climacteric women was considered very high $(86 \%$ ranking from moderate to severe) caused mostly by indecision, anhedonia, guilt, crying and self-esteem, followed by inutility, self-criticism and loss of concentration.
\end{abstract}

\section{Keywords}

Climacteric, Depression, Symptoms Hierarchy, Women's Health 


\section{Introduction}

Depression is defined as a normal human emotion, a clinical symptom and a group of syndromes or disturbances characterized by a painful or unpleasant affective state, with losses in motor, perceptive and cognitive performance: loss of interest and pleasure in the activities that used to be meaningful, reduction of energy, somatic anxiety, intermediate and terminal insomnia, reduction of sexual interest, psychomotor retardation, cognitive difficulty, loss of hope, reduction of self-esteem and recurrent thinking of death [1]. The probability of a man presenting a severe depressive disorder ranges from $5 \%$ to $12 \%$ and the probability of a woman presenting a grave depressive disorder varies from $10 \%$ to $25 \%$, during their lives [2]. It has long been recognized that women are at a higher risk than men of developing depression and that this risk is particularly associated with reproductive cycle events [3].

The hormonal changes in women [4] as their complain of climacteric and other sub-liminary symptoms are most frequently associated with psychic complaints [5]. Some comorbidities associated with menopause are [6] metabolic syndrome, high blood pressure, cardiovascular disease, obesity, cancer, low bone mineralization, arthritis and neurodegenerative disorders [7]. These factors contribute to the reduction of their autonomous functioning [8], compromising their self-esteem and self-image [9].

The Centers for Psycho and Social Attention (CAPS) [10] have a strategic value for the Brazilian Psychiatric Reform [11], as a substitute option to mental health hospitals [12]. They have shown effectiveness in the substitution of long-term internment that isolates patients from their family and the community [13]. Offering daily clinical support, such as access to a psychiatrist, they avoid admission into mental hospitals [14] and promote social inclusion and care for the subject as someone unique, with their own history, their personal culture and their daily needs [15].

Bearing in mind the higher prevalence of depression in women [16] [17] [18], considering that depression is commonly associated with climacteric [19] and that negative attitude towards menopause is associated with more frequently reported symptoms [20], investigating climacteric and its association with depression, observing their values and anguishes are of great relevance to establish humanized health programs.

With increased life expectancy, nowadays, women spend one-third of their life after menopause [21], and those with diagnosed menopause symptoms present higher medical and pharmacy costs as much as lower productivity [22]. Women in menopause should not be forgotten [19].

Therefore, the goal of the present study was to check the prevalence of depression and its most associated symptoms in climacteric women, served by the CAPS of Specialized Mental Medicine, in Sorocaba, Brazil.

\section{Methods}

The present cross-sectional research had its sample composed of climacteric 
women, selected among those served by CAPS of Specialized Mental Medicine, in Sorocaba. The sample of 48 climacteric women represented $65.75 \%$ of the climacteric population served by this CAPS. The inclusion criteria were: being attended by the referred to CAPS, and being in the climacteric. The exclusion criterion was self-disorientation, that was diagnosed by the psychiatrist responsible for the research. The application of the Beck Depression Inventory (BDI), after the signing of the consent forms, was done in the presence of the first author, a psychiatrist, during clinical ambulatory appointment, from March to October 2018.

The present study complies with the Rules for Research in Human Beings following the principles defined by the Helsinki Declaration [23] [24]. The research project was submitted to the Ethics Committee of the Institute of Medical Research and Study of the state of Minas Gerais-IPEMED_of the Medical University Gama Filho, UGF, and it was approved. Depression was evaluated via the Beck Depression Inventory (BDI), created by Aaron Beck, which has been validated internationally [25] as well as in Brazil [26]. Beck developed a triad of negative cognitions about the world, the future and the self which play a major role in depression, and the BDI comprises 21 questions with four answer options for each one $(0-3)$, therefore the total points score for the inventory can oscillate between zero and 63, where the highest score indicates the highest depression [27]. The score evaluation suggested by Beck is: a) 0 - 9 = no depression; b) $10-18=$ mild to medium depression; c) $19-29=$ medium to severe depression; d) $30-63=$ severe depression.

The statistical analysis included the descriptive statistics: mean, standard deviation and median. Spearman's correlation was calculated to verify the most significant symptoms in the determination of depression in the sample. The statistical results were presented as tables and graphics. For this statistical analysis, Excel and SPSS 16.0 software were used.

\section{Results}

Some socio-demographic characteristics and symptoms presented by these climacteric women are listed in Table 1.

At the conclusion of the BDI investigation, it was observed that the climacteric women presented frequency within the four levels of the Beck Depression Inventory, BDI, as displayed in Table 2.

As seen in Table 2, according to the levels defined by Beck, in the original project for the Beck Depression Inventory most of the population reported medium to severe or severe depression.

The BDI results provide a quantitative assessment of the intensity of depression, reflecting the depth of depression.

The descriptive analysis of the BDI score is presented in Figure 1. The medium score was 28.96 , with standard deviation equal to 11.41 ; its distribution showed relative symmetry, with a slightly bigger variation in the higher scores. 
The Spearman correlation results presented in Table 3 show the symptoms that contributed the most to the final score.

It can be seen in Table 3 that the most significant complaints ( $\mathrm{p}<0.001)$, and the ones that showed high average correlation were respectively (in decreasing order): indecision, anhedonia, guilt, crying and self-esteem. Sadness, pessimism, failures from the past, self-criticism, loss of interest in activities, inutility, loss of energy, irritability, loss of appetite, loss of concentration and tiredness and fatigue, all these topics showed an average Spearman index of correlation with depression complaints, with statistical significance. The exceptions were suicidal thoughts, loss of sexual interest, sleeping alteration, agitation and punishment.

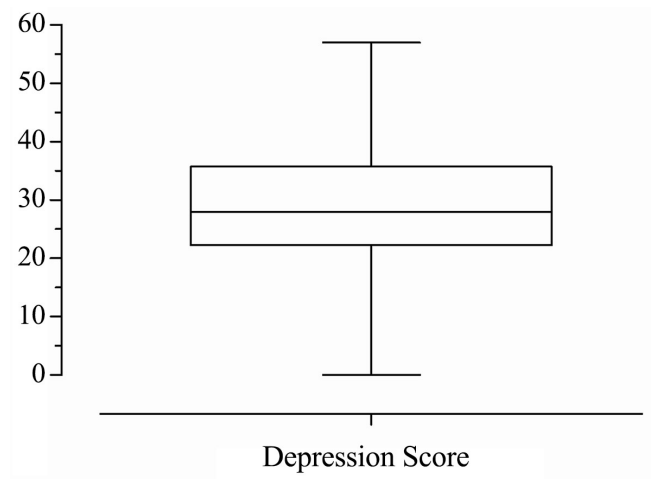

Figure 1. BOX-plot beck depression inventory.

Table 1. Sociodemographic characteristics and symptoms of the climacteric women.

\begin{tabular}{ccc}
\hline & Yes & No \\
\hline Smoking & $26 \%$ & $74 \%$ \\
Employed & $33 \%$ & $67 \%$ \\
Marital Partner & $28 \%$ & $72 \%$ \\
High School Level & $14 \%$ & $86 \%$ \\
Drug Addicted & $59 \%$ & $41 \%$ \\
Co-morbidities & $63 \%$ & $37 \%$ \\
Hormone Therapy & $61 \%$ & $39 \%$ \\
\hline
\end{tabular}

Table 2. BDI frequency distribution.

\begin{tabular}{ccc}
\hline Depression & Frequency & Percentage \\
\hline No Depression & 2 & 4.2 \\
Mild Depression & 5 & 10.4 \\
Medium Depression & 18 & 37.4 \\
Severe Depression & 23 & 48.0 \\
Total & 48 & 100 \\
\hline
\end{tabular}

Obs: BDI = Beck Depression Inventory. 
Table 3. Spearman correlation and statistical significance (p-value) between the symptoms and the final BDI score.

\begin{tabular}{|c|c|c|c|}
\hline Symptoms & $\begin{array}{l}\text { Spearman } \\
\text { Correlation }\end{array}$ & Classification & p-value \\
\hline Sadness & 0.50 & Average & $<0.001$ \\
\hline Pessimism & 0.47 & Average & $<0.001$ \\
\hline Failures from the past & 0.47 & Average & $<0.001$ \\
\hline Anhedonia & 0.66 & High Average & $<0.001$ \\
\hline Guilt & 0.63 & High Average & $<0.001$ \\
\hline Punishment & 0.18 & Low & 0.22 \\
\hline Self-esteem & 0.60 & High Average & $<0.001$ \\
\hline Self-criticism & 0.58 & Average & $<0.001$ \\
\hline Suicidal thoughts & 0.36 & Low Average & 0.01 \\
\hline Crying & 0.62 & High Average & $<0.001$ \\
\hline Agitation & 0.29 & Low Average & 0.05 \\
\hline Loss of interest in activities & 0.43 & Average & 0.002 \\
\hline Indecision & 0.72 & High Average & $<0.001$ \\
\hline Inutility & 0.59 & Average & $<0.001$ \\
\hline Loss of energy & 0.48 & Average & $<0.001$ \\
\hline Sleeping Alteration & 0.18 & Low & 0.22 \\
\hline Irritability & 0.49 & Average & $<0.001$ \\
\hline Loss of appetite & 0.45 & Average & 0.001 \\
\hline Loss of concentration & 0.57 & Average & $<0.001$ \\
\hline Tiredness and fatigue & 0.55 & Average & $<0.001$ \\
\hline Loss of sexual interest & 0.27 & Low Average & 0.06 \\
\hline
\end{tabular}

Because over $86 \%$ of the climacteric women who answered the inventory showed levels of moderate to severe depression in the Beck Depression Inventory, the self-evaluation of these climacteric women randomly selected among the ones served by the CAPS of Specialized Mental Medicine in Sorocaba can be considered very high.

\section{Discussion}

Researches show that among climacteric women, the symptoms and the more frequent psycho-physiological problems can be related to the lack of information, the life history and to the woman's family and cultural context [28]. The occurrence of climacteric complaints affects perceived health status [5], that is, the well-being and quality of a woman's life. Therefore, giving them knowledge of their new position in life can empower them to new strategies [29], and to a healthier living. 
Some women have a hormonal vulnerability to mood disorders; however, for menopausal depression, there appears to be a complex interplay between hormonal vulnerability, the psychosocial resources one has, physical activity and stressful life events [30]. It has been revealed that depression is lower during physical activity [31], and cross-sectional studies typically report a reduction in menopausal effects with physical activity, with active women reporting fewer or less severe symptoms [32]. Usually, depressed climacteric women report a painful past, a present where depression became their lives background, and a dark future perspective [33].

Transition to menopause and its changing hormonal milieu are strongly associated with a new onset of depressed mood among women with no history of depression [34]. Menopausal status remains an independent predictor of higher depressive symptoms [35] [36]. In this study, the climacteric women reported that indecision, anhedonia, guilt, crying and low self-esteem are the biggest causes of depression, which are essentially symptoms of climacteric, and there is strong evidence that psychological climacteric symptoms can be linked not only to hormonal but also to social factors that coincide with the menopause [37]. In Korea [38] and in South Africa [39], low self-esteem is the biggest cause of climacteric depression. From melancholia to "empty nest syndrome", an association between menopausal transition and the emergence of depression continues to be the focus of controversy [40]. The distinction between specific and non-specific symptoms may be useful for aetiological research on biological, psychological and environmental factors [41], as there is no scale to properly evaluate them nowadays [42].

Due to the high prevalence of depression in climacteric women [43], nowadays climacteric treatment considers the possibility of the use of antidepressant medication (except for vascular symptoms) [3] [44]. The contribution of reproductive hormones to mood has been the focus of considerable research, but results from clinical and epidemiological studies have been inconsistent, remaining unclear as to whether alterations in serum hormone levels across the menopausal transition are linked to depressive symptoms [35].

The most significant complaints reported by women in this research in decreasing order were: indecision, anhedonia, guilt, crying and self-esteem. Suicidal thoughts, loss of sexual interest, agitation and punishment did not show correlation or statistical relevance. Anhedonia (a loss of the capacity to feel pleasure) has been considered as a premorbid personological trait or as a main symptom of a picture of major depressive clinical [45]. It is a complex psychological condition related to major depression [46]. Contrary to our findings, in Seattle climacteric women's depressed mood is correlated with sleep disruption, difficulty with concentration and decreased sexual desire [47].

The climacteric women evaluated in this study, having been previously sent to a psychiatrist, and therefore presented a possible tendency toward significant psychiatric complaints, suggesting that depression findings in climacteric women can be lower than those found in this research, at least in gravity, though not 
in the specific reported complaints. Yet the elevated index of depressive symptoms found in this epidemiological research shows the importance of diagnosis and treatment for this condition, which frequently passes unknown.

It seems mandatory to treat depression in climacteric women by giving attention to the climacteric itself, focusing on the depression as much as treating the climacteric syndrome [44] [48] [49] [50], helping patients to manage their lives and deal with personal relationships [51]. Depression among climacteric women is an important public health problem that requires attention [52]. Scientific evidence contributes to a re-evaluation of depression and climacteric [44], and the mental health care needs to be integrated within all other health and social policy aspects as well as being considered in the health system planning.

Limitations of the present study include the fact that responsiveness was not assessed using an interventional design, a before and a after. Another limitation is that no external measure was considered to provide a reference of association with comorbidities. Limitations should also consider that we had to rely on patient and investigator ratings of overall depression severity, limitation common to self-report inventories, in that scores can be easily exaggerated or minimized.

\section{Conclusions and Recommendations}

The prevalence of depression self-evaluated by these climacteric women, randomly selected among those served by a CAPS Mental Specialized Medicine, is very high according to the levels defined by Beck, in his BDI project, and presents as the most significant complaints, in decreasing order, indecision, anhedonia, guilt, crying and self-esteem, followed by inutility, self-criticism and loss of concentration.

These complaints should be taken into consideration when dealing with that particular population. Attention referring to the conditions surrounding depression in climacteric women is a theme of social and scientific relevance.

It is suggested that services and projects attending climacteric women consider these specific scientific findings determined by the self-evaluation of the climacteric women regarding their depression.

With population aging worldwide and women having a higher life expectation nowadays, it is important to continue research in the field of depression, as well as on the neuropsychiatric problems of climacteric women, as the symptoms can be linked not only to hormonal and social factors, but also to other unknown factors.

\section{Conflicts of Interest}

The authors declare no conflicts of interest regarding the publication of this paper.

\section{References}

[1] Lindwall, M., Rennemark, M., Halling, A., Berglund, J. and Hassmén, P. (2006) De- 
pression and Exercise in Elderly Men and Women: Findings from the Swedish National Study on Aging and Care. Journal of Aging and Physical Activity, 15, 41-55. https://doi.org/10.1123/japa.15.1.41

[2] American Psychiatric Association. Diagnostic and Statistical Manual of Mental Disorders. DSM-IV 4 ed2000.

[3] Frey, B.N., Lord, C. and Soares, C.N. (2018) Depression during Menopausal Transition: A Review of Treatment Strategies and Pathophysiological Correlates. British Menopause Society, 14, 123-128. https://doi.org/10.1258/mi.2008.008019

[4] Aubertin-Leheudre, M., Goulet, E.D. and Dionne, I.J. (2008) Enhanced Rate of Resting Energy Expenditure in Women Using Hormone-Replacement Therapy: Preliminary Results. Journal of Aging and Physical Activity, 16, 53-60. https://doi.org/10.1123/japa.16.1.53

[5] Boulet, M.J., Oddens, B.J., Lehert, P., Vemer, H.M. and Visser, A. (2008) Climacteric and Menopause in Seven South-East Asian Countries. Maturitas, 61, 34-53.

[6] Palacios, S., Henderson, V., Siseles, N., Tan, D. and Villaseca, P. (2010) Age of Menopause and Impact of Climacteric Symptoms by Geographical Region. Climacteric, 13, 419-428. https://doi.org/10.3109/13697137.2010.507886

[7] Pérez-López, F.R., Chedraui, P., Haya, J. and Cuadros, J.L. (2009) Effects of the Mediterranean Diet on Longevity and Age-Related Morbid Conditions. Maturitas, 64, 67-79. https://doi.org/10.1016/j.maturitas.2009.07.013

[8] Castro, J.C., Giani, T.S., Ferreira, M.A., Bastos, F.A., Cruz, T.H., Boechat, R., et al. (2009) Depression in Inactive and Active Elderly Women Practitioners of Dance, Weight-Lifting or Meditation. Acta Medica Lituanica, 16, 52-57. https://doi.org/10.2478/v10140-009-0008-6

[9] Chattha, R., Raghuram, N., Venkatram, P. and Hongasandra, N.R. (2008) Treating the Climacteric Symptoms in Indian Women with an Integrated Approach to Yoga Therapy: A Randomized Control Study. Menopause, 15, 862-870. https://doi.org/10.1097/gme.0b013e318167b902

[10] Willrich, J.Q., Kantorski, L.P., Chiavagatti, F.G., Cortes, J.M. and Pinheiro G.W. (2011) Periculosidade versus cidadania: os sentidos da atenção à crise nas práticas discursivas dos profissionais de um Centro de Atenção Psicossocial; Periculosity and Citizenship: The Meanings of Attention to the Crisis in the Discursive Practices of the Psychosocial Healthcare Centers Professionals. Physis. Revista de Saúde Coletiva (Rio de Janeiro), 21, 47-64. https://doi.org/10.1590/s0103-73312011000100004

[11] Cordeiro, L.R.O., Oliveira, M.S. and de Souza, R.C. (2012) Produção científica sobre os Centros de Atenção Psicossocial. Revista da Escola de Enfermagem da USP, 46, 119-123. https://doi.org/10.1590/s0080-62342012000100016

[12] Onocko-Campos, R.T. and Furtado, J.P. (2006) Entre a saúde coletiva e a saúde mental: um instrumental metodológico para avaliação da rede de Centros de Atenção Psicossocial (CAPS) do Sistema Único de Saúde. Cadernos de Saúde Pública, 22, 1053-1062. https://doi.org/10.1590/s0102-311x2006000500018

[13] Hirdes A. (2009) A reforma psiquiátrica no Brasil: Uma (re) visão. Ciência \& Saúde Coletiva, 14, 297-305. https://doi.org/10.1590/s1413-81232009000100036

[14] de Fátima Nascimento, A. and Galvanese, A.T.C. (2009) Avaliação da estrutura dos centros de atenção psicossocial do município de São Paulo, SP. Revista de Saúde Pública, 43, 8-15. https://doi.org/10.1590/s0034-89102009000800003

[15] Rodrigues, J., Brognoli, F.F. and Spricigo, J.S. (2006) Associação dos usuários de um centro de atenção psicossocial: Desvelando sua significação. Texto \& Contex- 
to-Enfermagem, 15, 240-245. https://doi.org/10.1590/s0104-07072006000200007

[16] Kockler, M. and Heun, R. (2002) Gender Differences of Depressive Symptoms in Depressed and Nondepressed Elderly Persons. International Journal of Geriatric Psychiatry, 17, 65-72. https://doi.org/10.1002/gps.521

[17] Van de Velde, S., Bracke, P. and Levecque, K. (2010) Gender Differences in Depression in 23 European Countries. Cross-National Variation in the Gender Gap in Depression. Social Science \& Medicine, 71, 305-313. https://doi.org/10.1016/j.socscimed.2010.03.035

[18] Delisle, V.C., Beck, A.T., Dobson, K.S., Dozois, D.J. and Thombs, B.D. (2012) Revisiting Gender Differences in Somatic Symptoms of Depression: Much Ado about Nothing? PLoS ONE, 7, e32490. https://doi.org/10.1371/journal.pone.0032490

[19] Ceylan, B. and Özerdoğan, N. (2014) Menopausal Symptoms and Quality of Life in Turkish Women in the Climacteric Period. Climacteric, 17, 705-712. https://doi.org/10.3109/13697137.2014.929108

[20] Yanikkerem, E., Koltan, S.O., Tamay, A.G. and Dikayak, S. (2012) Relationship between Women's Attitude towards Menopause and Quality of Life. Climacteric, 15, 552-562. https://doi.org/10.3109/13697137.2011.637651

[21] Vaze, N. and Joshi, S. (2010) Yoga and Menopausal Transition. Journal of Mid-Life Health, 1, 56-58. https://doi.org/10.4103/0976-7800.76212

[22] Kleinman, N.L., Rohrbacker, N.J., Bushmakin, A.G., Whiteley, J., Lynch, W.D. and Shah, S.N. (2013) Direct and Indirect Costs of Women Diagnosed with Menopause Symptoms. Journal of Occupational and Environmental Medicine, 55, 465-470. https://doi.org/10.1097/jom.0b013e3182820515

[23] Goodyear, M., Krleza-Jeric, K. and Lemmens, T. (2007) The Declaration of Helsinki. British Medical Journal, 335, 624. https://doi.org/10.1136/bmj.39339.610000.be

[24] World Medical Association (WMA) (2008) Declaration of Helsinki: Ethical Principles for Medical Research Involving Human Subjects. Jahrbuch für Wissenschaft und Ethik, 14, 233-238. https://doi.org/10.1515/9783110208856.233

[25] Beck, A., Steer, R. and Carbin, M. (1998) Psychometric Properties of the Beck Depression Inventory: Twenty-Five Years of Evaluation. Clinical Psychology Review, 8, 77-100. https://doi.org/10.1016/0272-7358(88)90050-5

[26] Gorestein, C. and Andrade, L. (1996) Validation of a Portuguese Version of the Beck Depression Inventory and the State-Trait Anxiety Inventory in Brazilian Subjects. Brazilian Journal of Medical and Biological Research, 29, 453-457.

[27] Beck, A.T., Ward, C.H., Mendelson, M., Mock, J. and Erbaugh, J. (1961) An Inventory for Measuring Depression. Archives of General Psychiatry, 4, 561-571.

[28] Freitas, K.M., Silva, A.R.V. and Silva, R.M. (2004) Women in the Climacteric Phase. Acta Scientiarum Health Sciences, 26, 121-128.

[29] Landerdahl, M.C. (2002) Climateric Woman-A Necessary Approach at Basic Attention Level. Nursing, 47, 20-25.

[30] Gibbs, Z., Lee, S. and Kulkarni, J. (2012) What Factors Determine whether a Woman Becomes Depressed during the Perimenopause? Archives of Women's Mental Health, 15, 323-332. https://doi.org/10.1007/s00737-012-0304-0

[31] Chalder, M., Wiles, N.J., Campbell, J., Hollinghurst, S.P., Haase, A.M., Taylor, A.H., et al. (2012) Facilitated Physical Activity as a Treatment for Depressed Adults: Randomised Controlled Trial. BMJ: British Medical Journal, 344, e2758. https://doi.org/10.1136/bmj.e2758 
[32] Elavsky, S. and McAuley, E. (2007) Physical Activity and Mental Health Outcomes during Menopause: A Randomized Controlled Trial. Annals of Behavioral Medicine, 33, 132-142. https://doi.org/10.1007/bf02879894

[33] Beck, A.T. and Dozois, D.J. (2011) Cognitive Therapy: Current Status and Future Directions. Annual Review of Medicine, 62, 397-409. https://doi.org/10.1146/annurev-med-052209-100032

[34] Freeman, E.W., Sammel, M.D., Lin, H. and Nelson, D.B. (2006) Associations of Hormones and Menopausal Status with Depressed Mood in Women with No History of Depression. Archives of General Psychiatry, 63, 375-382. https://doi.org/10.1001/archpsyc.63.4.375

[35] Bromberger, J.T., Schott, L.L., Kravitz, H.M., Sowers, M.F., Avis, N.E., Gold, E.B., et al. (2010) Longitudinal Change in Reproductive Hormones and Depressive Symptoms across the Menopausal Transition: Results from the Study of Women's Health across the Nation (SWAN). Archives of General Psychiatry, 67, 598-607. https://doi.org/10.1001/archgenpsychiatry.2010.55

[36] Tangen, T. and Mykletun, A. (2008) Depression and Anxiety through the Climacteric Period: An Epidemiological Study (HUNT-II). Journal of Psychosomatic Obstetrics \& Gynecology, 29, 125-131. https://doi.org/10.1080/01674820701733945

[37] Pedro, A.O., Pinto-Neto, A.M., Costa-Paiva, L.H.S., Osis, M.J.D. and Hardy, E.E. (2003) Climacteric Syndrome: A Population-Based Study in Brazil. Revista de Saúde Pública, 37, 735-742. https://doi.org/10.1590/s0034-89102003000600008

[38] Lee, M.-S., Kim, J.-H., Park, M.S., Yang, J., Ko, Y.-H., Ko, S.-D., et al. (2010) Factors Influencing the Severity of Menopause Symptoms in Korean Post-Menopausal Women. Journal of Korean Medical Science, 25, 758-765. https://doi.org/10.3346/jkms.2010.25.5.758

[39] Compere, V. The Efficacy of Sepia $\hat{A}^{\circledast}$ in the Management of Climateric Symptoms.

[40] Soares, C.N. (2008) Depression during the Menopausal Transition: Window of Vulnerability or Continuum of Risk? Menopause, 15, 207-209 https://doi.org/10.1097/gme.0b013e31816381e9.

[41] Squelard, G., Missotten, P., Paquay, L., De Lepelerie, J., Buntinx, F., Fontaine, O., et al. (2012) Neuropsychiatric Inventory Data in a Belgian Sample of Elderly Persons with and without Dementia. Clinical Interventions in Aging, 7, 423-430. https://doi.org/10.2147/cia.s34948

[42] Zöllner, Y., Acquadro, C. and Schaefer, M. (2005) Literature Review of Instruments to Assess Health-Related Quality of Life during and after Menopause. Quality of Life Research, 14, 309-327. https://doi.org/10.1007/s11136-004-0688-Z

[43] Woods, N.F., Smith-DiJulio, K., Percival, D.B., Tao, E.Y., Mariella, A. and Mitchell, E.S. (2008) Depressed Mood during the Menopausal Transition and Early Postmenopause: Observations from the Seattle Midlife Women's Health Study. Menopause, 15, 223-232. https://doi.org/10.1097/gme.0b013e3181450fc2

[44] Graziottin, A. and Serafini, A. (2009) Depression and the Menopause: Why Antidepressants Are Not Enough? British Menopause Society, 15, 76-81. https://doi.org/10.1258/mi.2009.009021

[45] Pelizza, L. and Ferrari, A. (2009) Anhedonia in Schizophrenia and Major Depression: State or Trait. Annals of General Psychiatry, 8, 22. https://doi.org/10.1186/1744-859x-8-22

[46] Treadway, M.T. and Zald, D.H. (2011) Reconsidering Anhedonia in Depression: Lessons from Translational Neuroscience. Neuroscience \& Biobehavioral Reviews, 
35, 537-555. https://doi.org/10.1016/j.neubiorev.2010.06.006

[47] Woods, N.F., Smith-DiJulio, K., Percival, D.B., Tao, E.Y., Taylor, H.J. and Mitchell, E.S. (2007) Symptoms during the Menopausal Transition and Early Postmenopause and Their Relation to Endocrine Levels over Time: Observations from the Seattle Midlife Women's Health Study. Journal of Women's Health, 16, 667-677. https://doi.org/10.1089/jwh.2006.0138

[48] Greene, J.G. (2008) Constructing a Standard Climacteric Scale. Maturitas, 61, 78-84. https://doi.org/10.1016/j.maturitas.2008.09.011

[49] Soares, C.N. and Frey, B.N. (2010) Challenges and Opportunities to Manage Depression during the Menopausal Transition and beyond. Psychiatric Clinics of North America, 33, 295-308. https://doi.org/10.1016/j.psc.2010.01.007

[50] Studd, J. (2011) A Guide to the Treatment of Depression in Women by Estrogens. Climacteric, 14, 637-642.

[51] Horn, G.L. (2012) An Investigation into the Effects of Cognitive Behavioral Therapy on Patients with Chronic Depression: A Small Casa Series. Psychology Research and Behavior Management, 5, 123-129.

[52] Unsal, A., Tozun, M. and Ayranci, U. (2011) Prevalence of Depression among Postmenopausal Women and Related Characteristics. Climacteric, 14, 244-251. https://doi.org/10.3109/13697137.2010.510912 